\title{
Controle social do SUS: a saúde em região de fronteira em pauta'
}

\section{SUS social control: health in a border region on the agenda}

\author{
Natália Dias Alves Públio Hauma \\ (D) https://orcid.org/0000-0001-7061-1526 \\ E-mail: natpublioðgmail.com

\section{Manoela de Carvalho ${ }^{\mathrm{a}}$} \\ (D) https://orcid.org/0000-0003-4226-1332 \\ E-mail: manoelacarvœgmail.com \\ a Universidade Estadual do Oeste do Paraná (Unioeste). Foz do \\ Iguaçu, PR, Brasil.
}

\section{Resumo}

Este estudo analisa a dinâmica do exercício do controle social em município brasileiro de região de fronteira internacional a partir das atas do Conselho Municipal de Saúde (CMS), referentes às políticas de saúde específicas para a localidade. Empregou-se a técnica de análise documental auxiliada por instrumento elaborado para identificar a participação dos conselheiros em reuniões, atividades e temas relacionados à política de saúde na fronteira de 2006 a 2018, período relativo à adesão ao Sistema Integrado de Saúde das Fronteiras (SIS Fronteiras). Os resultados apontam que o CMS discutiu a política de saúde sem contextualizá-la suficientemente no território específico em que foi aplicada. Por conseguinte, recomenda-se mecanismos de formação para aprimorar a ação e organização, ancorados na temática saúde em regiões de fronteira, apoiando o exercício do controle social orientado para as necessidades da realidade local dos municípios brasileiros fronteiriços.

Palavras-chaves: Sistema Único de Saúde; Controle Social; Saúde na Fronteira.

\section{Correspondência




\section{Introdução}

Our study analyzes the dynamics of the exercise of social control in a Brazilian municipality in an international frontier region, based on the records by minutes of the Municipal Health Council (MHC), referring to specific health policies for the location. The document analysis technique was used, aided by an instrument designed to identify the participation of counselors in meetings, activities and topics related to health policy on the border from 2006 to 2018 , a period related to joining the Integrated Border Health System (SIS Fronteiras). The results indicate that the MHC discussed health policy without contextualizing it sufficiently in the specific territory of the border. Therefore, training mechanisms are recommended to improve action and organization, anchored on the health theme in border regions, supporting the exercise of social control oriented to the needs of the local reality of Brazilian border municipalities. Keywords: Unified Health System; Social Control; Formal; Border Health.
O Brasil possui área de fronteiriça compartilhada com 10 países sul-americanos. São 588 municípios distribuídos em 11 estados, dos quais 139 estão localizados no estado do Paraná. Os territórios de região de fronteira são complexos e devem ser entendidos além da esfera jurídica formal, no convívio cotidiano de espaços/limites, por coexistirem elementos de integração e de conflitos que precisam ser considerados na determinação social do processo saúde-doença e, portanto, nas políticas e programas de saúde para seu enfrentamento.

O território pode ser interpretado como um espaço social historicamente produzido e organizado, permeado por relações de poder por redes e identidades em constante transformação, agenciada principalmente pelo capital e Estado. A fronteira constitui um recorte analítico e espacial de diversas realidades políticas, econômicas e culturais que envolve o problema da volatilidade do capital e das relações de produção pelo território. A fronteira também é espaço de conflitos transculturais e identitários que carrega em sua história a preocupação com a segurança nacional e a carência de políticas públicas de cooperação transfronteiriça que promovam o desenvolvimento econômico integrado (Souza, 2013).

As políticas de saúde para as regiões de fronteira devem considerar a situação geopolítica marcada por assimetrias e desigualdades demonstradas em indicadores sociodemográficos e sanitários da população residente nessas áreas. Planejar gestão em saúde também deve considerar peculiaridades encontradas no território como instrumento para compreender dificuldades e necessidades típicas dessas regiões (Azevedo, 2015).

O Sistema Único de Saúde (SUS) organiza-se nacionalmente de forma descentralizada, observando as diferenças demográficas e socioeconômicas existentes no vasto território brasileiro, respeitando os princípios da universalidade do acesso e integralidade da assistência. Nesse sentido, o Decreto $\mathrm{n}^{0} 7 \cdot 508 / 2011$ visa regulamentar os papéis dos entes federativos nas regiões e redes de saúde, esclarecendo as responsabilidades e atribuições, os recursos financeiros, ações e serviços de saúde para garantir o efetivo direito à saúde no território. Para 
tanto, o decreto define como região de saúde "espaço geográfico contínuo constituído por agrupamentos de municípios limítrofes, delimitado a partir de identidades culturais, econômicas e sociais e de redes de comunicação e infraestrutura de transportes compartilhados, com a finalidade de integrar a organização, o planejamento e a execução de ações e serviços de saúde" (Brasil, 2011).

Com intuito de mobilizar gestores da área de saúde e expandir a capacidade operacional de 121 municípios fronteiriços, em 2005, o governo federal propôs o Sistema Integrado de Saúde das Fronteiras (SIS Fronteiras), implantando um sistema de cooperação em rede integrando as ações e serviços de saúde nas regiões de fronteira (LEMÕES et al., 2019). Por meio da colaboração internacional entre países fronteiriços, almejou-se promover, na área de saúde, práticas integradas e transformadoras para fortalecer sistemas bilateralmente.

Na gestão da saúde, o controle social tem um importante papel na consolidação dos princípios do SUS, exercido formalmente nas instâncias dos conselhos e conferências, servindo como espaço de debates, pactuações e deliberações nos quais a sociedade civil pode interferir na definição das políticas de saúde, considerando interesses do coletivo e necessidades locais de saúde.

Os Conselhos Municipais de Saúde (CMS), enquanto instrumentos de participação da sociedade civil, podem contribuir para a organização de uma rede de saúde local mais efetiva nas respostas aos problemas de saúde da população residente neste território e colaborar na elaboração de temas de interesse público regional, emergindo como espaço democrático para a manifestação da participação social. Nesse sentido, este estudo objetiva analisar a dinâmica do exercício do controle social em município brasileiro de região de fronteira internacional.

\section{Metodologia}

Estudo descritivo de abordagem qualitativa, baseado em análise documental, fundamentado na apreciação das atas das reuniões do Conselho Municipal da Saúde de Foz do Iguaçu (COMUSFOZ) a partir de 2006, período de implantação do SIS Fronteiras. 0 recorte temporal foi intencional, pois o
SIS Fronteiras foi uma política pública importante e específica para municípios em regiões de fronteiras que possibilitou ou intensificou o debate sobre questões relacionadas ao território de fronteira e às políticas de saúde. A pesquisa documental foi realizada com material que ainda não recebeu um tratamento analítico em relação a um determinado objeto de estudo (Cechinel et al., 2016).

o COMUSFOZ foi criado pela Lei Municipal $\mathrm{n}^{0} 1.507 / 1990$. É integrado por três segmentos sociais e por representação paritária de 50\% representantes de entidades de usuários, $25 \%$ trabalhadores em serviços de saúde, 12,5\% gestores de órgãos públicos de saúde e 12,5\% prestadores de serviços de saúde, totalizando 32 membros titulares e 32 membros suplentes, indicados pelas entidades/órgãos eleitas em Conferência Municipal de Saúde (Foz do Iguaçu, 2012).

O SIS Fronteiras foi uma proposta lançada pelo governo brasileiro com intuito de minimizar assimetrias administrativas vigentes e com objetivo principal de fortalecer serviços de saúde nos 121 municípios de fronteira. Nesse contexto, segundo Hortelan et al. (2019), "acordos binacionais, cidadania de estrangeiros e programas/políticas dirigentes sobre atendimento aos transfronteiriços [...]" (p. 235) potencializam serviços de saúde e conduzem planejamento e ações do gestor de saúde pública. Por conseguinte, fez-se uso deste programa como marcador das discussões sobre políticas de saúde específicas para região de fronteira no CMS pesquisado.

Foram analisadas 282 atas e selecionadas 77 que mencionavam "saúde e fronteira", "políticas de saúde na fronteira" e/ou "SIS Fronteiras", incluindo participação dos conselheiros em eventos ou capacitações relacionadas à saúde na fronteira. Na Figura 1, apresenta-se o procedimento de análise dos dados para a extração das categorias de análise e unidades temáticas abordadas nos resultados.

Utilizou-se instrumento elaborado para coleta e sistematização dos dados. Para análise do conteúdo foi empregado o referencial de Bardin (2016) que propõe tratar informações brutas em reproduções que proporcionem auxiliar o acesso, consulta e referência aos documentos examinados, seguidas das etapas pré-análise, exploração do material e tratamento dos dados. As categorias analíticas organizadas tinham a finalidade de identificar 
participação dos conselheiros em reuniões, assim como atividades e discussões relacionadas à política de saúde na fronteira a partir do período de adesão ao SIS Fronteiras. Operam como categorias analíticas: (1) políticas de saúde na fronteira, (2) SIS Fronteiras e (3) participação dos conselheiros em capacitações com a temática saúde na fronteira (Figura 01); e, como unidades temáticas, foram analisadas: (1.1) assistência à saúde da população na fronteira, (2.1) prestações de contas dos recursos do SIS Fronteiras, (2.2) ações financiadas pelo SIS Fronteiras, (2.3) plano operativo e (2.4) comissão local de Saúde do SIS Fronteiras, em razão de terem sido as mais expressivas para o alcance do objetivo desse estudo.

Os aspectos éticos da pesquisa seguem o proposto pela Resolução $n^{0}$ 510/2016 do Conselho Nacional da Saúde (CNS). 0 projeto foi aprovado pelo Comitê de Ética em Pesquisa com Seres Humanos sob parecer $n^{0} 2.982 .939 / 2018$.

\section{Figura I - Fluxograma referente às etapas das análises das atas do COMUSFOZ relacionadas à saúde e à fronteira}

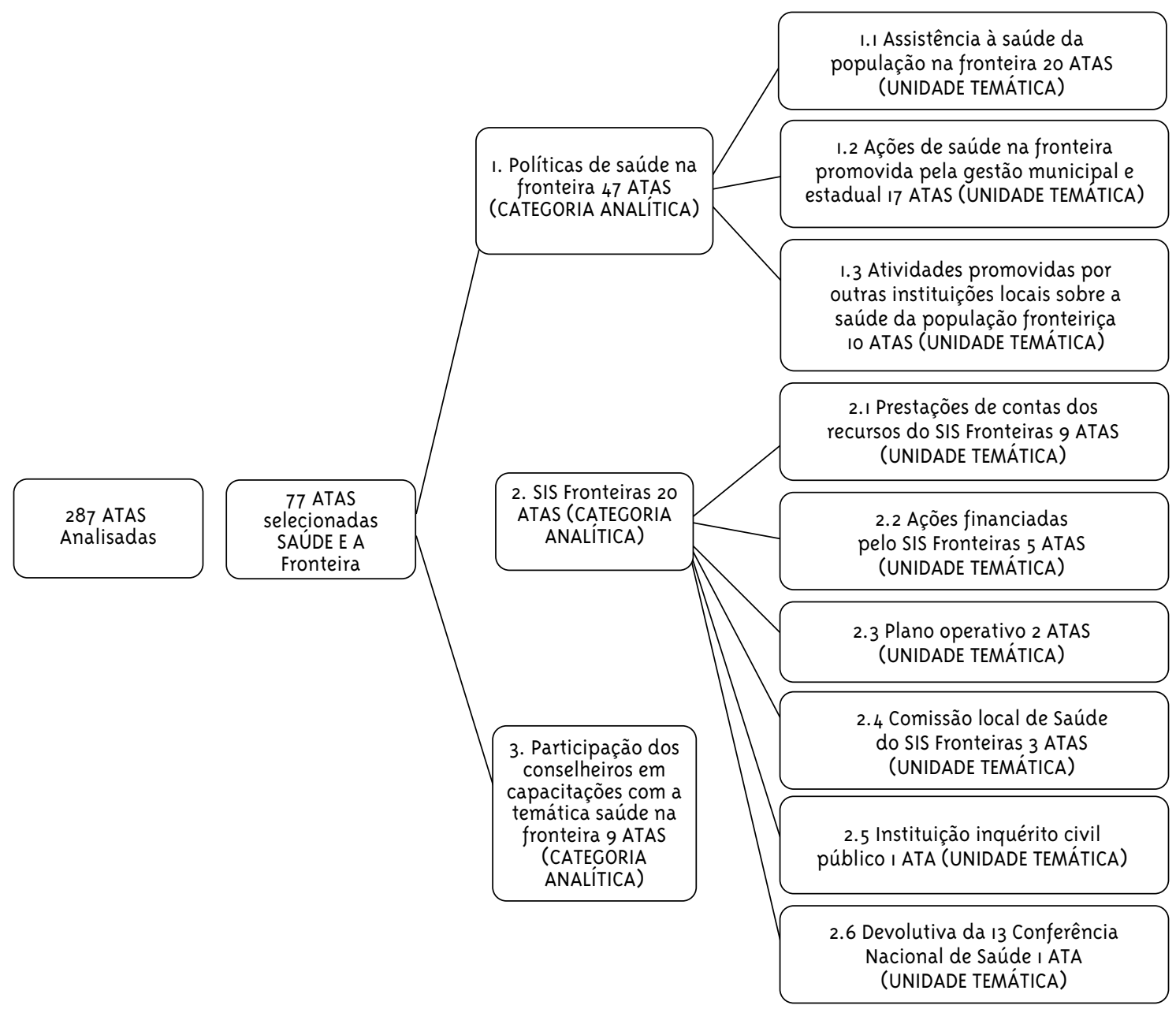

\section{Resultados}

Os espaços de debate dos CMS têm fundamental importância para o controle social, fiscalizando as políticas de saúde e influenciando o desenvolvimento regional. No Quadro 1 são apresentados os resultados das análises dos documentos obtidos nas atas do COMUSFOZ, procurando compreender como essa entidade abordou o tema da saúde em região de fronteira. 


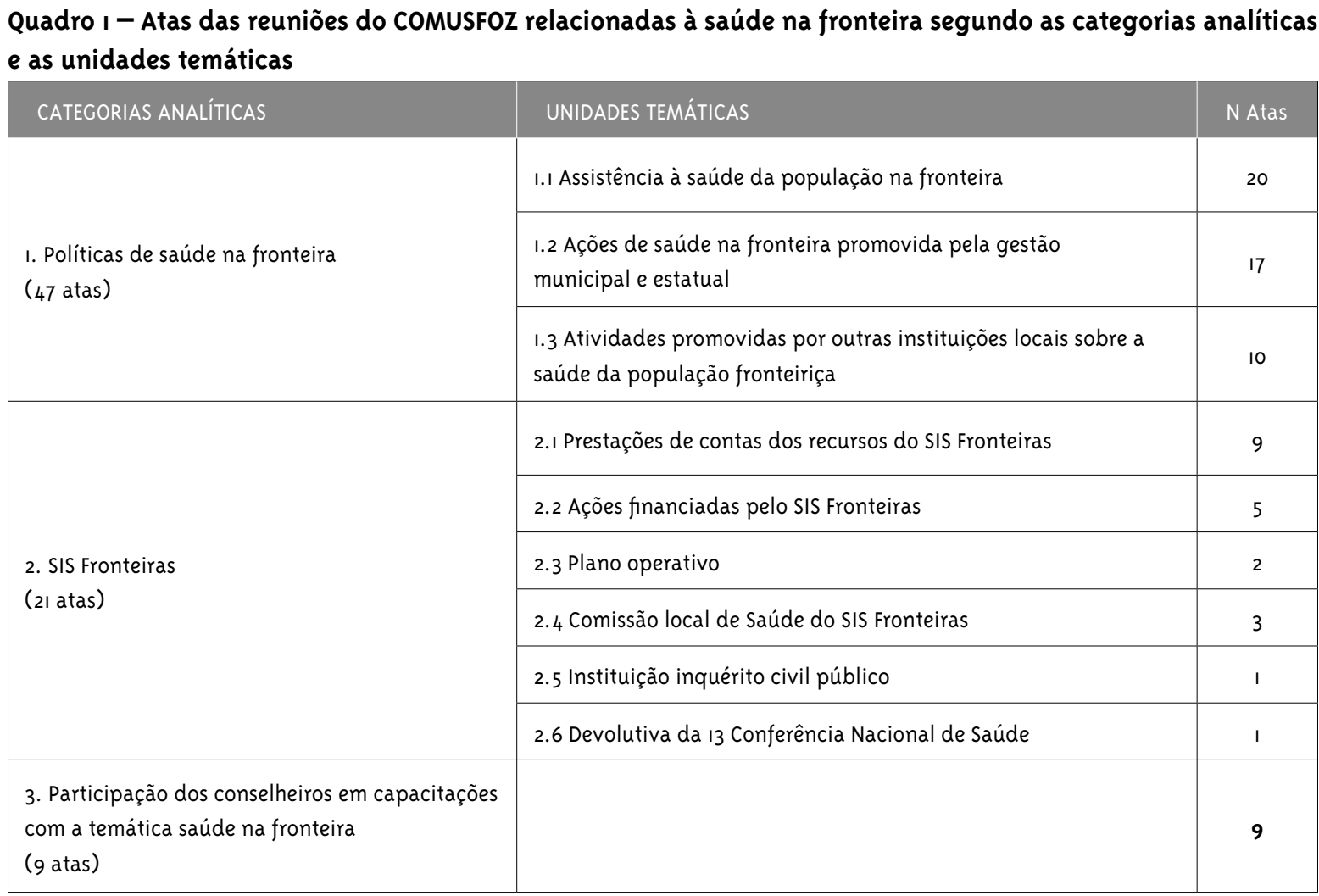

\section{Políticas de saúde na fronteira}

Há registros sobre políticas de saúde na fronteira em 47 atas (Quadro 1), em 20 delas a unidade temática assistência à saúde da população na fronteira se destacou. Na pauta da reunião $n^{0} 339 / 2006$, cuja ordem do dia refere à situação assistencial atual do município:

Internações hospitalares, conforme paramentos do Ministério da Saúde para cada 1 mil habitantes é recomendado disponibilizar 2,5 a 3,o leitos, considerando a população atual do município é superior a 300 mil habitantes, sem contar a expressa massa de 'brasiguaios', cerca de $250 \mathrm{mil}$ cidadãos brasileiros residem na faixa de fronteira em território paraguaio recorrem em grande número aos serviços médico-hospitalares locais. (Foz do Iguaçu, 2006).

Em 2008, foram encontrados registros na Ata $n^{0} 418$ sobre atendimentos realizados pela Santa
Casa Monsenhor Guilherme, quando os conselheiros questionaram o tamanho da população atendida no município em relação ao número de leitos disponibilizados. Além da população residente no município, eles também argumentavam o atendimento de não residentes com destaque aos "brasiguaios" (brasileiros residentes no Paraguai) e interrogavam sobre financiamento federal para a saúde do município que não beneficiava a população transfronteiriça no repasse de verba.

Existem atendimentos prestados aos brasileiros residentes no Paraguai, sendo que o Ministério da saúde não considera esses atendimentos, portanto valores destinados ao município são baseados em 311 mil habitantes, mas a SMSA sabe que são atendidas aproximadamente 40 mil pessoas, que não estão contempladas nesta estatística. (Foz do Iguaçu, 2008)

Nos registros de reuniões destinadas a deliberar sobre o orçamento da Secretaria Municipal de 
Saúde, identificou-se que representantes da gestão municipal também questionaram atendimentos à população não residente nos serviços de saúde do município.

Conforme Relatório do IBGE, Foz do Iguaçu contempla uma população de 256 mil habitantes, mas a Saúde atende aproximadamente 270 mil pacientes que estão cadastrados no Programa Saúde Foz e 4o mil destes pacientes não são moradores de Foz do Iguaçu. Se levarmos em conta os pacientes que têm Plano de Saúde corporativo o município tem uma população de 320 mil habitantes. Conforme relatório apresentado, o município atende pacientes de outros municípios, estados e até de outros países, por exemplo, os brasileiros residentes do outro lado das fronteiras assim como os estudantes da UNILA. $^{2}$ (Foz do Iguaçu, 2012)

O reconhecimento da distinção dos orçamentos públicos, destinados aos sistemas locais de saúde em municípios de fronteira, é uma preocupação dos gestores municipais de saúde recorrentemente expressa nas atas devido à não contabilização da população flutuante nos dados para os repasses financeiros. Em reunião registrada na Ata n ${ }^{0}$ 355/2006 para tratar do Pacto de Gestão e Orçamento 2007 da Secretaria Municipal de Saúde, o tema fronteira aparece como parte da apresentação do gestor municipal que diz:

As regiões fronteiriças obrigatoriamente há um envolvimento especial do Ministério da Saúde que deve envidar esforços no sentido de promover articulação entre os países e órgãos envolvidos na perspectiva da implementação do SUS e consequentemente organização da atenção nos municípios fronteiriços, coordenando e fomentando a constituição dessas regiões e participando do colegiado de gestão regional... é o espaço permanente de pactuações visando uma rede regional de ações e serviços de atenção à saúde integrada e resolutiva, o colegiado de Bipartite regionais deverá ser constituído por todos os gestores municipais da regional, devendo instituir processo de planejamento regional que expresse responsabilidades do gestor com a saúde da população. (Foz do Iguaçu, 2006)

Ainda nessa reunião, o gestor explica o objetivo do Pacto de Gestão, além de explanar as funções do colegiado de gestão e as prioridades de cada ente federativo em relação às políticas de saúde, reforçando o compromisso com a gestão do sistema nos aspectos da descentralização, regionalização, financiamento, planejamento, programação pactuada integrada, regulação, participação social e gestão do trabalho em relação à saúde. Concernente às regiões de fronteiras, a resolução ministerial inclui atenção à saúde nos municípios fronteiriços, promovendo articulação entre os países e instituições envolvidas.

Apesar dessa reunião, registrada em Ata $n^{0} 355 / 2006$, tratar como pauta o pacto de gestão não evidenciou registros de participação efetiva dos conselheiros municipais de saúde, questionando ou argumentando pactuações e acordos bilaterais possíveis de serem negociados nos colegiados de gestão regional. Também não foram encontradas outras atas com registros de reuniões, encontros ou eventos promovidos por esse colegiado para tratar da assistência à saúde na fronteira, houve ausência do tema nas atas dos anos seguintes até 2018.

\section{SIS Fronteiras}

No COMUSFOZ foram encontrados registros sobre o SIS Fronteiras em 21 atas (Quadro 1), a primeira discussão sobre o programa constava na Ata $n^{0} 340$ da reunião de 09/03/2006, a pauta do encontro era a indicação de conselheiros para comissão local de saúde do SIS Fronteiras:

[...] iniciou a explanação da pauta sobre o SIS Fronteiras, dizendo que trata-se de um projeto já pactuado com o Ministério da Saúde, através da

2 A Universidade Federal da Integração Latino-Americana é um órgão de natureza jurídica autárquica, vinculada ao Ministério da Educação, com sede e foro em Foz do Iguaçu-PR. Sua missão é formar recursos humanos aptos a contribuir com a integração latino-americana, com o desenvolvimento regional e com intercâmbio cultural, científico e educacional da América Latina, especialmente no (Mercosul). Dos 5.890 estudantes da universidade, 1.549 deles são de 29 países diferentes (Kateivas, 2020). 
Portaria $\mathrm{n}^{0} 1.120$, e informa que para instituir o programa deve-se observar alguns itens, citando o Ministério que repassou R\$ 436 mil este valor deve ser utilizado pelo município na melhoria da rede básica de saúde e implantar os serviços, que busquem viabilizar ações aos brasileiros que vivem do outro lado das fronteiras, Paraguai e Argentina. (Foz do Iguaçu, 2006)

$\mathrm{Na}$ reunião citada, o gestor apresentou os objetivos do programa, as três fases que contemplam a execução, exibiu valores de repasses financeiros e a instituição de uma comissão. De acordo com os registros, o programa apresenta no seu Art. $1^{\circ}$ institui o SIS Fronteiras, sendo este destinado a integrar as ações e serviços de saúde nas regiões de fronteira, com os seguintes objetivos:

I. Contribuir para o fortalecimento e organização dos sistemas locais de saúde;

II. Verificar as demandas e a capacidade instalada; III. Identificar os fluxos de assistência;

IV. Analisar o impacto das ações desenvolvidas sobre a cobertura e a qualidade assistencial;

V. Documentar os gastos com assistência aos cidadãos;

VI. Integrar os recursos assistenciais físicos e financeiros.(Foz do Iguaçu, 2006)

Consta ainda na ata que o município receberia proveniente do orçamento federal o montante de R\$ 6,5 milhões, valor advindo do Projeto de Formação e Melhoria da Qualidade da Rede de Atenção à Saúde (QualiSUS) para o desenvolvimento do SIS Fronteiras, que se desenvolveria em três fases: diagnóstico e plano operacional, implantação de serviços para áreas de fronteiras e qualificação da gestão em áreas estratégicas. 0 gestor informou que uma das exigências do Ministério da Saúde seria a instituição do Comitê Permanente de Implementação e Acompanhamento das Ações do SIS Fronteiras, que no COMUSFOZ foi constituído por representantes de entidades nacionais e dos países vizinhos:

[...] representantes da SMSA, membros do COMUS,

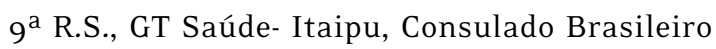

de Cidade Del Leste, Consulado Brasileiro em Porto Iguaçu, Secretaria Municipal de Relações Internacionais, Hospital Costa Cavalcante, Hospital Cataratas, Pastoral do Migrante e Pastoral da Saúde do Paraguai. (Foz do Iguaçu, 2006)

De acordo com registros da Ata $n^{0}$ 340/2006, o objetivo principal dessa reunião foi instituir a comissão permanente, que deveria ser decidida de maneira imediata mesmo após apresentação da estrutura do programa, conforme esclarecido pelo gestor.

[...] a proposta é que o COMUSFOZ indique os nomes e aprove esta comissão, com urgência para ser repassado os indicados ao Ministério da Saúde para que esta comissão inicie os trabalhos... primeiro vamos conhecer a realidade e repassar estas informações ao Ministério da Saúde, esclarecendo que hoje só estamos criando a comissão e inclusão do município no programa, e o SIS Fronteiras, está dividido em três fases, lembrando que no dia de hoje não estamos pedindo aprovação dos serviços, após concluído o diagnostico é que vamos começar implantar os serviços. (Foz do Iguaçu, 20o6)

$\mathrm{Na}$ leitura das atas selecionadas a partir do marcador fronteira, encontrou-se discussões relacionadas às prestações de contas dos recursos do SIS Fronteiras nos registros de 9 atas, ações financiadas pelo SIS Fronteiras em 5, plano operativo em 2 e referente à Comissão local de Saúde do SIS Fronteiras em 3.

O plano operativo foi apreciado pelos conselheiros municipais em reunião de Ata nº 358/2006.

Foz do Iguaçu foi o primeiro município do Brasil a concluir este projeto e este diagnóstico feito pela Universidade Federal do Paraná em conjunto com o Ministério da Saúde, a UFPR ouviu 42 mil usuários do SUS em um determinado período na cidade do dia 14/08/2006 a o8/o9/2006, em cima desses dados e considerações do COMUSFOZ nos seus segmentos, o Ministério da Saúde chegou ao diagnóstico do município. (Foz do Iguaçu, 2006) 
Durante essa reunião, o gestor explicou como foi realizado o estudo para chegar ao diagnóstico do município pela Universidade Federal do Paraná.

Foi feito um raio-x não somente em relação a saúde da população, mas sobre a classe econômica dos moradores do município. Os usuários das unidades básica de saúde que foram entrevistados do SUS para fins da pesquisa foram; Núcleo de Saúde da A.K.L.P, UBS do Jardim América, UBS da Vila Iolanda, Núcleo de Saúde do São João e Profilurb II, Hospital Costa Cavalcante, Pronto Atendimento 24h Central e Morumbi I. Essas 42 mil pessoas responderam uma pesquisa qualitativa que tem muito mais dados e responsabilidades das informações, sendo importante para o Ministério da Saúde formular uma política de Saúde. À medida que integram o município de Foz do Iguaçu com municípios de fronteira, se não houver uma regulamentação correrá riscos em função da demanda. (Foz do Iguaçu, 2006)

Conforme os registros, a pesquisa realizada para definir o diagnóstico local também apresenta dados referentes à nacionalidade das pessoas que buscaram os serviços e ao perfil do atendimento prestado para essa população durante o período do estudo.

[...] 42.258 desse número de usuários 651 são paraguaios, 82 argentinos e 257 outras nacionalidades, sendo $98.7 \%$ desses estrangeiros são residentes no Brasil, 1.1\% no Paraguai e o\% na Argentina. Receberam atendimentos 89.1\%, agendadas $6.6 \%$, orientados para atendimentos em outros serviços de saúde no mesmo município $2.1 \%$. Não receberam atendimento e nenhum tipo de orientação 394 pessoas. Em relação ao tratamento oncológico 52.720 são brasileiros, 52 paraguaios, 1 argentino e 5 de outras nacionalidades. (Foz do Iguaçu, 2006)

$\mathrm{Na}$ ata ainda constam registros de resultados encontrados pela pesquisa que realizou o diagnóstico do sistema de saúde local quanto ao acesso (se precisou de ajuda de terceiros para obter atendimento) e o nível de satisfação:
[...] [ajuda de] religiosa 44, família 314, políticos 7 , movimentos sociais 8 [...]. Os resultados obtidos relatam $96 \%$ da população entrevistada estão satisfeitas com os atendimentos ofertados, precisando ser melhorado. Explica que a maior parte dos recursos, ainda é destinada para as questões curativas. (Foz do Iguaçu, 20o6)

Em relação aos recursos financeiros, a ata registra os valores que seriam repassados pelo Ministério da Saúde e para onde deveriam ser destinados:

R\$1,215 milhão são para equipar e construir UBS tem uma sobra de recursos para o SIS Fronteiras de R\$436 mil pelo diagnóstico, não foram gastos nem $\mathrm{R} \$ 150$ mil sobrando em torno de R\$30o mil que serão repassados para fase 2 que após aprovação do plano operativo será revertido na construção das UBS do Jardim América e Jardim Jupira. Os investimentos de R\$330 mil seriam para investir em cursos para profissionais da atenção básica tanto na urgência quanto emergência e área hospitalar, capacitando permanentemente a equipe de saúde. 0 aumento de leitos hospitalares concluindo assim o Hospital Municipal são um valor de aproximadamente R\$3,3 milhões aprovado pela comissão do SIS Fronteiras, dentre outras questões prioritárias para o município de Foz do Iguaçu citadas. (Foz do Iguaçu, 2006)

O plano operacional habilita o município para receber recursos do Ministério da Saúde e, após ser apresentado pelo representante da Secretaria de Saúde, foi colocado em apreciação e aprovado pelos conselheiros municipais de saúde. A fase I do SIS Fronteiras homologada através da Portaria $\mathrm{n}^{0} 160 / 2007$, diz:

Art. $1^{\circ}$ Homologar a Fase I do Sistema Integrado de Saúde das Fronteiras - SIS FRONTEIRAS, que compreende o Diagnóstico Local e o Plano Operacional do Município de Foz do Iguaçu (PR). Art. $2^{\circ}$ Autorizar a utilização do saldo remanescente da Fase I, no valor de R\$367.o82,15 (trezentos e sessenta e sete mil oitenta e dois reais e quinze centavos), de recursos de custeio, bem como de seus 
rendimentos decorrentes da aplicação financeira, para a execução da Fase II do SIS FRONTEIRAS.

Art. $3^{\circ}$ Autorizar o repasse dos recursos correspondentes à Fase II do SIS FRONTEIRAS destinado ao Município de Foz do Iguaçu (PR), que corresponde a R\$508.908,40 (quinhentos e oito mil novecentos e oito reais e quarenta centavos), conforme previsto na Portaria $\mathrm{n}^{0} 1.189 / \mathrm{GM}$, de 05/o6/2006. (Brasil, 2007b)

Essa reunião configurou o momento de maior discussão do SIS Fronteiras pelos conselheiros. Outros registros vinculados ao programa aparecem nas prestações de contas pontualmente: poucas falas por parte dos conselheiros questionando a demora no repasse de verbas para as construções das unidades de saúde que foram contempladas no plano e um único apontamento em ata de solicitação pela secretaria de saúde para apreciação de alterações no plano de aplicação de recursos.
O último registro referente ao programa ocorreu em ata no ano de 2011 (Quadro 2), que tratava de repasses financeiros para contemplar a construção de duas unidades de saúde. Nota-se, em 2006, quando o programa foi implantado no município, até 2011, quando o assunto aparece pela última vez, que a discursão do SIS Fronteiras ficou restrita às questões financeiras, não havendo registros sobre elaboração de políticas de saúde na fronteira contemplando o objetivo do programa de promover integração de ações e serviços de saúde na região, prevista na Portaria $n^{0}$ 1.188/2006. Também não há registro de outras necessidades previstas, como a avaliação de ações compartilhadas na área de saúde no âmbito das fronteiras, o desenvolvimento de um sistema de informação como suporte para um sistema de cooperação e a mobilização dos gestores da área de fronteira para definição e implementação de um sistema de cooperação em rede (Brasil, 20o6).

Quadro 2 - Atas do COMUSFOZ sobre o SIS Fronteiras, Foz do Iguaçu, 2006 a 2018

\begin{tabular}{|c|c|c|c|}
\hline ANO & N Atas analisadas & $\begin{array}{l}\text { N Atas nas quais } \\
\text { aparecem registros } \\
\text { sobre o SIS-Fronteira }\end{array}$ & Assuntos tratados \\
\hline 2006 & 30 & 05 & $\begin{array}{l}\text { (ol) Prestação de contas } \\
\text { (ol) Plano operativo } \\
\text { (o3) Comissão local de saúde }\end{array}$ \\
\hline 2007 & 31 & 04 & $\begin{array}{l}\text { (02) Prestação de contas } \\
\text { (o1) Ações financiadas pelo SIS Fronteiras } \\
\text { (o1) Devolutiva da I3 Conferência Nacional de Saúde }\end{array}$ \\
\hline 2008 & 29 & 07 & $\begin{array}{l}\text { (05) Prestação de contas } \\
\text { (oı) Ações financiadas pelo SIS Fronteiras } \\
\text { (oı) Instituição de inquérito civil público }\end{array}$ \\
\hline 2009 & 12 & 03 & $\begin{array}{l}\text { (o1) Prestação de contas } \\
\text { (02) Ações financiadas pelo SIS Fronteiras }\end{array}$ \\
\hline 2010 & 06 & ০o & Sem registros* \\
\hline 2011 & 15 & 02 & $\begin{array}{l}\text { (oı) Plano operativo } \\
\text { (oı) Ações financiadas pelo SIS Fronteiras }\end{array}$ \\
\hline 2012 & 17 & oo & Sem registros* \\
\hline 2013 & 22 & ০o & Sem registros* \\
\hline 2014 & 26 & o० & Sem registros* \\
\hline
\end{tabular}




\begin{tabular}{|c|c|c|l|}
\hline ANO & N Atas analisadas & $\begin{array}{c}\text { N Atas nas quais } \\
\text { aparecem registros } \\
\text { sobre o SIS-Fronteira }\end{array}$ & Assuntos tratados \\
\hline 2015 & 23 & 00 & Sem registros* \\
\hline 2016 & 25 & 00 & Sem registros* \\
\hline 2017 & 24 & 00 & Sem registros* \\
\hline 2018 & 22 & 00 & Sem registros* \\
\hline
\end{tabular}

* Nos anos 2010 e 2012 a 2018 não foram encontrados registros sobre o SIS-Fronteiras nas atas analisadas.

Mesmo após adesão do município ao SIS Fronteiras, considerando esse um programa propulsor da discussão sobre o sistema de saúde em região de fronteira e momento de maior discussão no âmbito do Conselho Municipal referente à saúde na fronteira, registros posteriores não revelaram uma consolidação desse debate no espaço do COMUSFOZ.

\section{Participação dos conselheiros em capacitações com a temática saúde na fronteira}

A Política de Educação Permanente em Saúde (PEPS), reformulada em 2007 com participação do CNS, deliberou as diretrizes para a Política Nacional de Educação Permanente para o Controle Social no SUS, buscando fomentar ampliação de iniciativas existentes das instituições e impulsionar estados e municípios na procura de qualificação para seus conselheiros (Brasil, 2007a).

As participações dos conselheiros do COMUSFOZ em atividades de qualificação foram identificadas a partir do registro de atividades internas em 9 atas promovidas pela mesa diretora do CMS e atividades externas através de convites partindo, na maioria das vezes, de instituições de ensino superior e o GT-SAUDE ${ }^{3}$ para participação em cursos, seminários, fóruns e palestras.
O tema saúde em região de fronteira aparece em apenas 9 atas nas quais constam atividades de qualificação com a participação dos conselheiros:

[...] informa sobre o Simpósio Internacional de Direito a Saúde na UNILA, coordenado por um advogado do curso de saúde coletiva... com a presença de representantes do Ministério da Saúde, Ministério Público e outros países, o foco vai ser o direito a saúde do estrangeiro em Foz do Iguaçu, principalmente em relação a tríplice fronteira, acredito ser um tema importante para os conselheiros estarem presentes. (Foz do Iguaçu, 2015)

Com relação especificamente ao SIS Fronteiras, parte dos recursos oriundos do programa proporcionou cursos de capacitação para servidores públicos municipais, mas não para conselheiros, no seguinte formato:

Realizou 3 cursos de capacitação aos servidores da rede de saúde, direcionada a médicos, auxiliares e técnicos de enfermagem e usuários, realizados com recursos do SIS Fronteiras, abrangendo acolhimento, o que é a enfermagem, psicologia e apresentando toda rede de saúde. (Foz do Iguaçu, 2009)

3 Grupo de Trabalho para Integração das Ações de Saúde na Área de Influência da Itaipu, criado em 2003, com objetivo de constituir um espaço democrático de trabalho e debates sobre saúde da região da tríplice fronteira (Brasil-Paraguai-Argentina), baseado na cooperação e integração entre os países, no respeito às diretrizes dos sistemas nacionais de saúde e com ênfase na atenção básica em saúde. A Itaipu aporta recursos financeiros para custeio das atividades administrativas do GT Saúde, trabalha com metodologia participativa, envolvendo profissionais da saúde dos três países (PERON, 2017). 
Foram encontrados registros sobre o QUALIFOZ, um curso de formação promovido pelo COMUSFOZ cujo objetivo é contemplar a política de educação permanente para o controle social na saúde do município de Foz do Iguaçu. O curso segue a estrutura do QUALICONSELHOS com emissão de certificado pela Escola Nacional de Saúde Pública Sérgio Arouca (Fundação Oswaldo Cruz), oferta anualmente para conselheiros municipais com carga horária de 100 horas-aula e aborda questões relacionadas às políticas públicas de saúde local e no Brasil, tais como financiamento, principais programas e serviços e outras políticas locais, porém, até o presente, o curso ainda não contemplava a temática saúde na fronteira na programação. A ata consultada afirmava: “[...] Informou que está com duas turmas do Qualifoz-2018, com aulas até final de novembro, mais de 60 alunos inscritos este ano" (Foz do Iguaçu, 2018).

Entre as ações de qualificações ofertadas para os conselheiros municipais e as promovidas pelo COMUSFOZ, não houve registros sobre o tema saúde na fronteira e o assunto é pouco explorado por outras instituições que, através de convites, propiciam a participação pontual dos conselheiros municipais.

\section{Discussão}

A formação de um território expressa a apropriação e as relações sociais que ocorrem no espaço geográfico, envolvendo poder. Território é, portanto, espaço geográfico socialmente construído e transformado historicamente pelas sociedades que o ocupam. Cada território possui uma identidade que o caracteriza e implica no sentido de territorialidade entre os cidadãos que ali vivem. Os territórios em regiões de fronteira brasileira são espaços singulares que devem ser analisados como forma diferenciada de organização territorial no bojo da ordem territorial capitalista com importantes repercussões nos fluxos transfronteiriços (Souza; Gemelli, 2011). As fronteiras são espaços privilegiados e específicos, com componentes marcantes desde sua ocupação até o (des)encontro com o "Outro" e as decorrências dessas relações que podem ser expressas em disputas e conflitos étnicos e sociais. Na inexistência do conflito, também deixariam de existir as fronteiras, pois, ao mesmo tempo em que é linha de separação, é fluida e porosa para atender às necessidades dos sujeitos que habitam esse espaço (Kleinschmitt; Azevedo; Cardin, 2013).

Estudo com gestores municipais de saúde em região de fronteira aponta o financiamento de ações e serviços de saúde como fator decisivo para ampliar ou restringir o acesso a estrangeiros e sugere repasse extra por procedimento realizado em usuário estrangeiro, Piso de Atenção Básica (PAB) especial para a população não contabilizada, registros e instituição de sistema de informação para atendimento ao estrangeiro e estruturação da gestão e do financiamento (Aikes; Rizzotto, 2018).

O SUS é organizado de maneira hierarquizada e regionalizada, garantindo aos gestores municipais a instituição de consórcios intermunicipais para ações e serviços de saúde em conjunto. 0 pacto pela saúde na dimensão do pacto de gestão propiciou um avanço ao abranger as regiões de fronteira em seu plano de regionalização, garantindo acesso universal e igualitário aos serviços de saúde e expandindo a governabilidade dos gestores municipais (SantosMelo et al., 2020).

$\mathrm{O}$ pacto de gestão determina um conjunto de reformas institucionais, firmado entre os três entes federativos com proposito de viabilizar renovações nos métodos e dispositivos de gestão, fortalecendo assistência à saúde, garantindo acesso universal e igualitário. Salientando modificações na efetivação do SUS, entre elas: “[a] regionalização solidária e cooperativa como eixo estruturante do processo de descentralização; integração das várias formas de repasse dos recursos federais; e unificação dos vários pactos hoje existentes” (Preuss, 2018, p. 329).

A legislação sanitária vigente após a instituição do SUS, observa as diferenças intraterritoriais no Brasil e busca formular dispositivos legais para amparar a ação dos gestores e do controle social na perspectiva de incorporar tais características no planejamento das políticas de saúde. Assim propõe o Decreto $n^{0} 7 \cdot 508 / 2011$ quando estabelece a estrutura organizativa do SUS, o planejamento e a assistência à saúde e a articulação interfederativa, buscando ampliar as condições de acesso ao direito à saúde em todo o País. No entanto, alguns obstáculos persistem na concretização dos princípios do SUS (Oliveira et al., 2019). 
Para assegurar acesso universal e integral aos serviços de saúde ao cidadão, as regiões de saúde foram instituídas, considerando em suas definições o cotidiano dos indivíduos, onde moram e transitam, envolvendo em sua negociação os três entes federativos (Preuss, 2018). O intuito destes dispositivos é expandir a condução operacional dos gestores municipais quanto ao acesso universal e integral às ações de saúde para cidadãos estrangeiros (Nogueira; Fagundes, 2014).

A ausência de registros nas atas a partir de 2012 expressa a desativação do SIS Fronteiras. Por meio da Portaria no 622/2014, o Ministério da Saúde requisitou o encerramento gradativo das ações previstas nos Planos Operacionais de todos os municípios beneficiados com recursos advindos do SIS Fronteiras, ou seja, à medida que as ações foram sendo realizadas, o programa foi se encerrando nos municípios de fronteira (Brasil, 2014). Após as ações desenvolvidas e as aquisições realizadas, esta política foi desativada e os municípios voltaram a ficar desprovidos de uma política de saúde específica para as regiões de fronteiras (Fabriz, 2019, p. 46).

Como fruto do financiamento do SIS Fronteiras, o município de Foz do Iguaçu construiu uma Unidade Básica de Saúde e reformou outra, promoveu cursos de aperfeiçoamento da gestão e custeou parcialmente o Centro Materno Infantil (Foz do Iguaçu, 2010). Não se localizou nas atas as discussões que definiram esses serviços.

Na política de saúde, os CMS configuram-se como espaços que possibilitam a participação da população na formulação e controle das políticas públicas de saúde, representando a intervenção da sociedade civil na gestão do SUS. Freitas e Souza, Ferreira e Oliveira (2019, p. 519) revelam a importância da qualificação para os dirigentes da gestão pública de saúde. Para os autores, "há um grande percentual de conselheiros que desenvolvem atividades no CMS e não possuem capacitação na área e a própria comunidade não é bem orientada sobre seu direito de opinar e fiscalizar as ações de saúde que lhe rodeiam”. Santos-Melo et al. (2020) concluem como fator limitante das principais estratégias de cooperação em saúde o desconhecimento dos gestores locais sobre acordos de cooperação estabelecidos entre os governos federais. Este estudo contou com a participação de um presidente do CMS no contexto da tríplice fronteira entre Brasil, Colômbia e Peru.

A PEPS pressupõe a modificação efetiva do cotidiano do setor saúde, na qual aprender e ensinar congregam-se aos afazeres habituais, empregando métodos ativos de ensino-aprendizagem (Fakhouri; Francischetti; Vieira, 2017). Ela pode ser direcionada aos trabalhadores, gestores e usuários do SUS, inclusive com intuito de estimular o controle social efetivo sobre as políticas de saúde.

Salientando a importância da educação permanente, Gomes et al. (2018) afirmam que a qualificação do exercício do controle social para os conselheiros municipais de saúde contribui para a qualificação da construção de políticas públicas ajustadas com a realidade local e com princípios e diretrizes do SUS.

\section{Considerações finais}

As análises das atas do COMUSFOZ de 2006 a 2018 apontaram que as especificidades relacionadas à saúde em região de fronteira receberam pouca atenção dos agentes que compõem o controle social na saúde do município de Foz do Iguaçu. Mesmo com adesão do SIS Fronteiras pela gestão local e com aprovação do plano operativo do programa no CMS, a estruturação de políticas públicas voltadas para a saúde na fronteira ainda não é uma realidade.

Vale ressaltar que, apesar de o SIS Fronteiras ter sido abordado no estudo como "objeto - marcador" do exercício do controle social de uma política direcionada para a região fronteiriça, foi possível identificar que este programa não consolidou um debate permanente entre os conselheiros municipais de saúde. Faltou capacitação ao longo do período para que o COMUSFOZ pudesse exercer controle mais efetivo sobre o SIS Fronteiras, além da homologação do programa.

Destacou-se que o COMUSFOZ adota a dinâmica do QUALIFOZ, curso estruturado pelo QUALICONSELHOS, mas também não inclui na programação o tema saúde em região de fronteira. Nesse aspecto, os conselheiros devem capacitar-se para esta atribuição, isto é, conhecer os princípios do SUS, condições de vida e de trabalho da região que impactam na determinação do perfil sanitário e as funções de conselheiro. Conhecer a realidade local é um dos quesitos fundamentais para exercer 
o controle social e, se tratando de um município localizado em tríplice fronteira internacional, compreender tratados internacionais, acordos bilaterais e relações de integração entre países para o setor saúde colaboram para exercício do controle social atentos às necessidades de saúde na fronteira.

No sentido de ampliar a capacidade desta população frente ao fortalecimento do exercício do controle social para saúde em região de fronteira, sugere-se incluir na dinâmica de formação dos conselheiros municipais de saúde conteúdos para compreensão das políticas de saúde na fronteira. Atividades como as desenvolvidas pela Fundação Oswaldo Cruz, que recentemente lançou o curso de atualização à distância, tratam a saúde em regiões de fronteiras a partir de uma abordagem interdisciplinar, considerando temas atuais em saúde e conexões com o cenário internacional, podendo contribuir para ampliar a visão crítica e participativa sobre política de saúde na fronteira, apoiando a atuação dos conselheiros municipais de saúde nas necessidades específicas desse território.

\section{Referências}

AIKES, S.; RIZZOTTO, M. L. F. Integração regional em cidades gêmeas do Paraná, Brasil, no âmbito da saúde. Cadernos de Saúde Pública, Rio de Janeiro, v. 34, n. 8, p. eoo182117, 2018. DOI: 10.1590/0102-311X00182117

AZEVEDO, S. T. s percepções sobre a saúde na fronteira Brasil e Paraguai: os transfronteriços e o atendimento pelo SUS. 2015. In: ENCONTRO NACIONAL DA ANPEGE, v. 11, 2015, Presidente Prudente. Anais [...]. Presidente Prudente:

ANPEGE, 2015.

BRASIL. Ministério da Saúde. Portaria no 1.188 , de 05 de junho de 2006. Dá nova redação a Portaria $\mathrm{n}^{0} 1.12 \mathrm{O} / \mathrm{GM}$, que instituiu o Sistema Integrado de Saúde das Fronteiras - SIS FRONTEIRAS. Diário Oficial da União, Brasília, DF, 6 jun. 2006. Disponível em: <https://bit.ly/32iRyCr >. Acesso em: 4 dez. 2019.

BRASIL. Política Nacional de Educação Permanente para o controle social no Sistema Único de Saúde SUS. Brasília, DF: Ministério da Saúde, 2007a.
BRASIL. Ministério da Saúde. Portaria nº 16o, de 22 de janeiro de 2007. Homologa a Fase I do SIS FRONTEIRAS, que compreende o Diagnóstico Local e o Plano Operacional do Município de Foz do Iguaçu (PR). Diário Oficial da União, Brasília, DF, 23 jan. 2007b. Disponível em: <https://bit.ly/ 3uVBwuz>. Acesso em: 16 abr. 2021.

BRASIL. Decreto $\mathrm{n}^{0} 7 \cdot 508$, de 28 de junho de 2011. Regulamenta a Lei $\mathrm{n}^{\circ}$ 8.080, de 19 de setembro de 1990, para dispor sobre a organização do Sistema Único de Saúde (SUS), o planejamento da saúde, a assistência à saúde e a articulação interfederativa, e dá outras providências. Diário Oficial da União, Brasília, DF, 29 jun. 2011. Disponível em: <https:// bit.ly/3aecgYS>. Acesso em: 15 set. 2020.

BRASIL. Ministério da Saúde. Portaria nº 622, de 23 de abril de 2014. Dispõe sobre os prazos para conclusão da implementação das ações previstas no Sistema Integrado de Saúde das Fronteiras (SIS Fronteiras) e sobre o repasse de incentivo financeiro. Diário Oficial da União, Brasília, DF: 28 abr. 2014. Disponível em: <https://bit.ly/ 3UYJRxP>. Acesso em: 13 abr. 2020.

CECHINEL, A. et al. Estudo/análise documental:

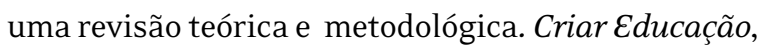
Criciúma, v. 5, n. 1, 2016. DOI: 10.18616/ce.v5i1.2446

FABRIZ, L. A. Sistema Integrado de Saúde nas fronteiras entre o Brasil e o Paraguai, no estado do Paraná: um estudo avaliativo. 2019. Tese (Doutorado em Enfermagem em Saúde Pública) Universidade de São Paulo, Ribeirão Preto, 2019.

FAKHOURI, A. P.; FRANCISCHETTI, I.; VIEIRA, C. M. Proposta de educação permanente para conselheiros municipais de saúde: relato de experiência. Revista Baiana de Saúde Pública, Salvador, v. 40, n. 4, p. 1029-1040, 2017. DOI: 10.1590/1983-1447.2017.01.58779 FOZ DO IGUAÇU. Plano Municipal de Saúde: 2010/2013. Foz do Iguaçu: Secretaria Municipal de Saúde, 2010.

FOZ DO IGUAÇU. Regimento Interno do Conselho Municipal de Saúde no município de Foz do Iguaçu-PR. Foz do Iguaçu: Secretaria Municipal de Saúde, 2012. 
FREITAS e SOUZA, M.; FERREIRA, T. F.; OLIVEIRA, Ronally Dart. Crise do capital e dos desafios para o controle social da saúde. Revista Direitos, Trabalho e Política Social, Cuiabá, v. 5 , n. 8, p. 57-77, 2019.

GOMES, A. M. et al. Reflexões e produção coletiva sobre o "ser" conselheiro municipal de saúde. Revista Brasileira de Enfermagem, Brasília, DF, v. 71, p. 538-547, 2018. Supl. 1. DOI: 10.1590/0034-7167-2017-0369

HORTELAN, M. S. et al. Papel do gestor de saúde pública em região de fronteira: scoping review. Acta Paulista de Enfermagem, São Paulo, v. 32, n. 2, p. 229-236, 2019. DOI: 10.1590/1982-0194201900031

KATEIVAS, M. Unila completa 10 anos com quase 30\% de alunos estrangeiros. G1 Oeste e Sudoeste, 13 jan. 2020. Disponível em: <https:// glo.bo/2RF4kJF>. Acesso em: 15 abr. 2021.

KLEINSCHMITT, S. C.; AZEVEDO, P. R.; CARDIN, E. G. A tríplice fronteira internacional entre Brasil, Paraguai e Argentina: contexto histórico, econômico e social de um espaço conhecido pela violência e pelas práticas ilegais. Revista Perspectiva Geográfica, Cascavel, v. 8, n. 9, 2013.

LEMÕES, M. A. M. et al. Mais médicos no programa de fronteira: gestão da saúde nas cidades gêmeas entre Brasil e Uruguai. Revista Uruguaia de Enfermagem, Montevidéu, v. 14, n. 1, p. 38-48, 2019. DOI: rue2019v14n1a44

NOGUEIRA, V. M. R.; FAGUNDES, H. S. A implementação do SIS Fronteiras-Perspectivas para a ampliação do direito à saúde na fronteira arco sul. Serviço Social e Saúde, Campinas, v. 13, n. 2, p. 24526o, 2014. DOI: 10.20396/sss.v13i2.8634903

OLIVEIRA, R. A. D. de et al. Barreiras de acesso aos serviços em cinco Regiões de Saúde do Brasil: percepção de gestores e profissionais do Sistema Único de Saúde. Cadernos de Saúde Pública, Rio de Janeiro, v. 35, n. 11, p. eoo120718, 2019. DOI: 10.1590/0102-311X00120718.

PERON, V. D. Cooperação Internacional e Política Públicas: a atuação do GT-Saúde na Tríplice Fronteira. 2017. In: SEMINÁRIO DA PÓSGRADUAÇÃO RELAÇÕES INTERNACIONAIS
CONTEMPONÂNEAS, 1., 2017, Foz do Iguaçu. Anais [...]. Foz do Iguaçu: Universidade Federal da Integração Latino-Americana, 2017.

PREUSS, L. T. A gestão do Sistema Único de Saúde no Brasil e as regiões de fronteira em pauta. Revista Katálysis, Florianópolis, v. 21, n. 2, p. 324-335, 2018. DOI: 10.159o/1982-02592018v21n2p324

SANTOS-MELO, G. Z. et al. Integração em saúde: cooperação na tríplice fronteira internacional amazônica. Revista de Saúde Pública, São Paulo, v. 54, p. 5, 2020. DOI: 10.116o6/s15188787.2020054001306

SOUZA, E. B. C. Por uma cooperação transfronteiriça: algumas contribuições para as dinâmicas territoriais da fronteira BrasilParaguai. Revista GeoPantanal, Campo Grande, v. 8, n. 15, p. 63-78, 2013.

SOUZA, E. B. C.; GEMELLI, V. Território, região e fronteira: análise geográfica integrada da fronteira Brasil-Paraguai. Revista Brasileira de Estudos Urbanos e Regionais, São Paulo, v. 13, n. 2, p. 101-116, 2011. DOI: 10.22296/2317-1529.2011v13n2p101

\section{Contribuição dos autores}

Haum contribuiu na concepção e desenho do estudo, aquisição; análise e interpretação de dados do estudo; elaboração e revisão crítica do conteúdo intelectual do estudo; aprovação da versão final do estudo a ser publicado. Foi responsável por todos os aspectos do estudo, assegurando as questões de precisão ou integridade de qualquer parte do estudo. Carvalho contribuiu na concepção $e$ desenho da pesquisa; obtenção, análise e interpretação dos dados; elaboração e revisão crítica do conteúdo intelectual do estudo; aprovação da versão final do estudo a ser publicado.

Recebido: 18/09/2020

Reapresentado: 18/09/2020

Aprovado: 27/01/2021 